\title{
The research of bearing capacity of reinforced concrete beam with use combined experimental-computational method
}

\author{
Olga Nekora ${ }^{1}$, Vitaliy Slovynsky ${ }^{1}$, and Serhii Pozdieiev ${ }^{1 *}$ \\ ${ }^{1}$ Cherkassy Institute of Fire Safety named after Chernobyl Heroes National University of Civil \\ Protection of Ukraine, 18000 Cherkassy, Ukraine
}

\begin{abstract}
The article shows results of behavior research of reinforced concrete beam exposed to fire using standard "time-temperature" curve. Practice of fire resistance estimating for reinforced concrete beams based on experimental and calculation method was developed and tested on the basis of the study results. Block diagram of temperature determining algorithm for nodal points of the cross-section by interpolation of temperature values in measurement points of the cross-section was showed. The fire test of reinforced concrete beams was carried out and a temperature distribution in cross-section of beams was defined based on it by application of interpolation techniques developed. The sequence of procedures of the strength calculation method based on temperature measuring in the inner layers of reinforced concrete beams was demonstrated. Fire resistance of the reinforced concrete beams under question was evaluated based on the interpretation of the data obtained during the fire tests and using the proposed method of strength calculating.
\end{abstract}

\section{Timeliness}

Due to a large volume of construction in our country, complexity and increased risk of accidents for people, who stay in buildings, in case of fire, there are many crucial issues to reduce the risk of injuries and deaths in case of collapse of building structures.

One of the main sources of risk in building structures due to fire heat exposure is low design safe load factor for such extreme conditions. Collapse of structures is of particular danger for people staying in a building for a time longer than the one required for the structure to exhaust its strength resources. Such people are exposed to danger during evacuation, especially when it is difficult, as the personnel of rescue units engaged in localization and liquidation of fire in the building are. Bent structural elements in such circumstances are of the greatest danger of collapse. Reinforced concrete beams are among these elements, as they have the largest size and load.

Taking into account all aforementioned, it can be noted that increasing fire safety of building structures is connected with improving of forecasting methods of reinforced concrete elements including reinforced concrete beams behavior for these conditions based

\footnotetext{
* Corresponding author: svp chipbbk@ukr.net
} 
on tests for fire resistance [ 1 to 3]. Therefore, study of patterns of temperature distribution in cross-sections of reinforced concrete beams during the fire resistance test is a critical task.

\section{Analysis of recent achievements and publications}

In the work [4] the approach proposed is lying in testing without application of mechanical stress for further calculating interpretation of temperature measurements by solving a strength task. The strength task can be solved using revised and simplified calculation methods [5], but use of any of them means the need to determine temperature distribution in each point of cross-section. It is necessary to develop a method of interpolation of temperatures in every point of the cross-section of reinforced concrete columns by temperature measuring during the tests carried out in specific measurement points of the inner layers in order to implement the method of data interpretation fire tests.

The objective of the research is formulated in this regard.

The objective is to develop methods of calculating strength on the basis of temperature measuring in the inner layers of reinforced concrete beam during standard fire resistance tests without application of mechanical load.

High-temperature testing of two identical sample beams was carried out within the testing stand, which is shown in Fig. 1, in order to exercise procedures for developed methods of interpolation.

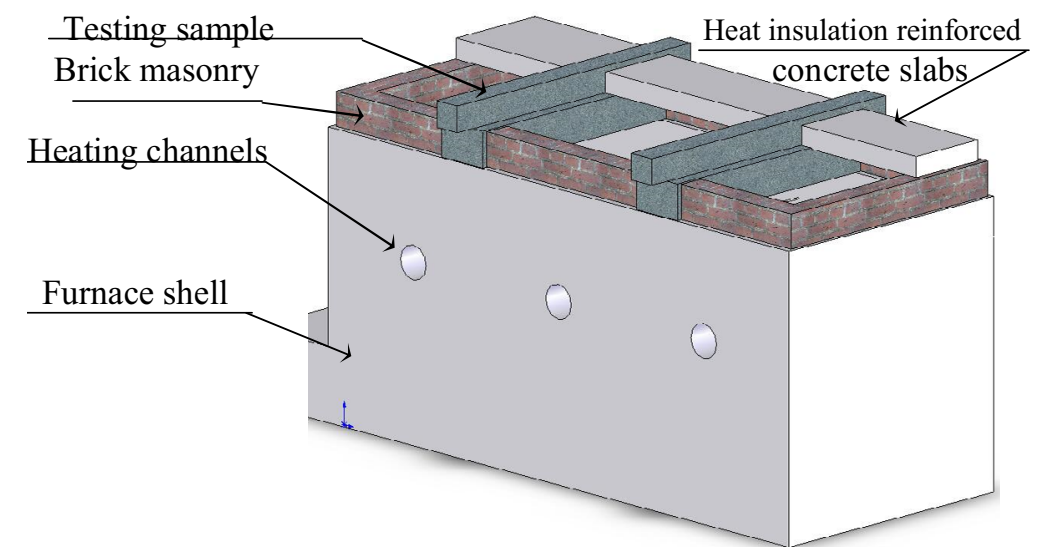

Fig. 1. Structure and appearance of the testing stand.

Sample reinforced concrete beams for testing were the beam elements having folds for placing of reinforced concrete panels into them. Sample beam dimensions are the following: length is $2560 \mathrm{~mm}$; width $-400 \mathrm{~mm}$; height $-450 \mathrm{~mm}$. Fig. 3 shows their cross-sectional geometry and layout of reinforcement bars.

According to the technical documentation a reinforced concrete beam should be made of concrete of C 30/35 (B30) grade. Fig. 3 shows the layout of temperature sensors for temperature measuring in inner layers of the reinforced concrete beams.

Below the results of the beam tests, the results of interpolation, and the results of study of interpolation adequacy are given.

In order to acquire temperature distribution pattern in the reinforced concrete beam cross-section using the acquired data the following algorithm was used, see Fig. 2 [4]. 


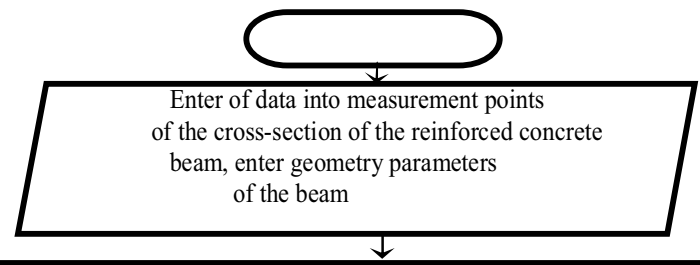

Determine curvature degree of parabolas that indicate temperature

distribution along measurement points lines: $\mathrm{Q}_{\mathrm{g}}$ - along horizontal measurement line;

$\mathrm{Q}_{\mathrm{v}}$ - along vertical measurement line; $\mathrm{Q}_{\mathrm{d}}$ - along main diagonal line.

according to approximation expressions $T_{g, k}=T_{0 k}+\left(T_{g \max _{k}}-T_{0 k}\right)\left[\frac{i}{n}\right]^{Q_{g}} ; T_{v, k}=T_{0 k}+\left(T_{v \max k}-T_{0 k}\right)\left[\frac{i}{n}\right]^{Q_{v}}$;

$$
T_{d, k}=T_{0 k}+\left(T_{d \max k}-T_{0 k}\right)\left[\frac{i}{n}\right]^{Q_{d}} \text { when } \Phi=\frac{1}{n} \sum_{i=1}^{m}\left[T_{i M}-T_{i E}\right]^{2} \rightarrow \min
$$

$\downarrow$

Divide the cross-section into a regular mesh with rectangular cells and nodal points lying

at the main diagonal line. Determine initial coordinates of the parabola origin for every

nodal point $y_{0}=\left[\left(T_{d k}-T_{0}\right)\left(T_{v k}-T_{0}\right)^{-1} d_{0}^{Q v}\right]_{v}^{Q_{v}^{-1}} ; x_{0}=\left[\left(T_{d k}-T_{0}\right)\left(T_{g k}-T_{0}\right)^{-1} d_{0}^{Q g}\right]^{Q_{g}^{-1}}$

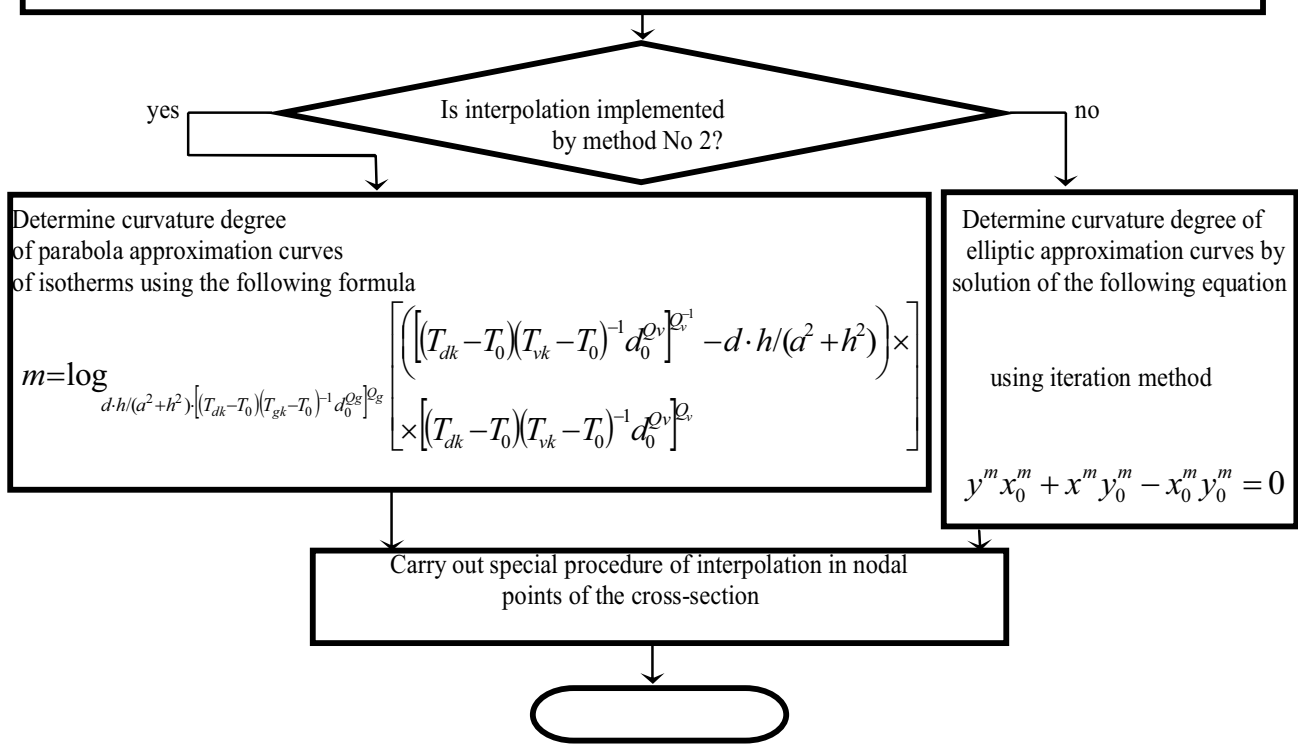

Fig. 2. Block diagram of temperature determining algorithm for nodal points of the cross-section by interpolation of temperature values in measurement points of the cross-section.

After interpolation using the developed techniques the following temperature distributions were obtained, see Fig. 4.

To determine the load capacity a technique considering deformation model [4] was applied. Material properties were taken into consideration with recommendations provided by the second part of Eurocode 2 [5]. The calculations found that reduction of bearing capacity for investigational crossbars No. 1 and No. 2 (using different methods of interpolation, shown in Fig. 5) is time-dependent. These calculations show that the limit state of bearing capacity loss for both beams has been achieved. The limit condition was determined with regard to rated bending moment applied to the beams under question, according to the technical specifications (about 0.3 of destroying load) $\mathrm{N}=50 \mathrm{kNm}$. 

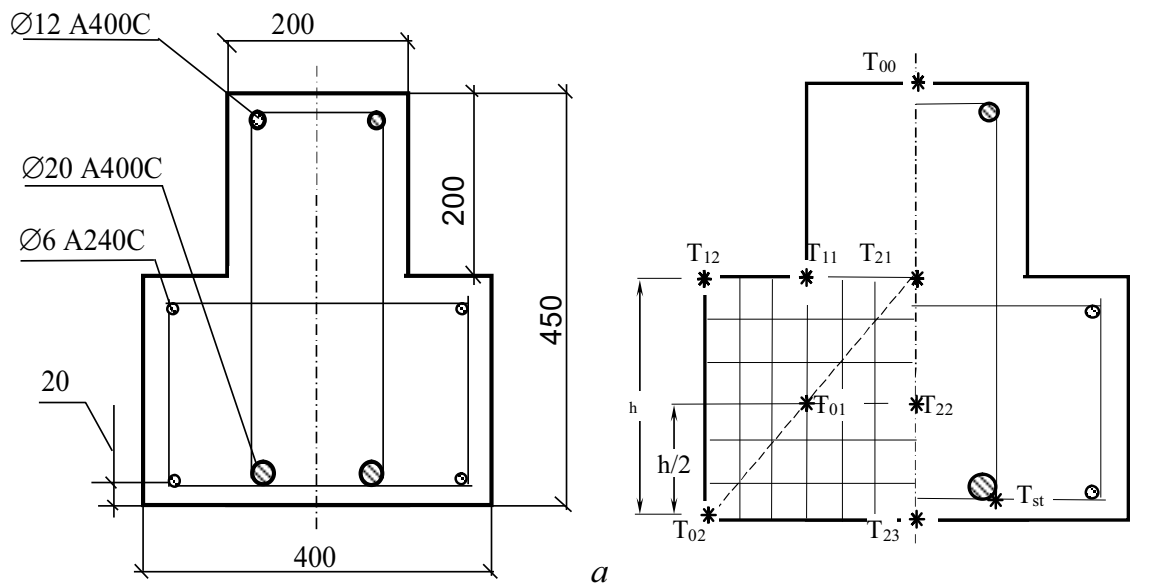

Fig. 3. Cross-sectional geometry (a) and layout of thermocouple sensing elements (b) of the beam for testing purposes.
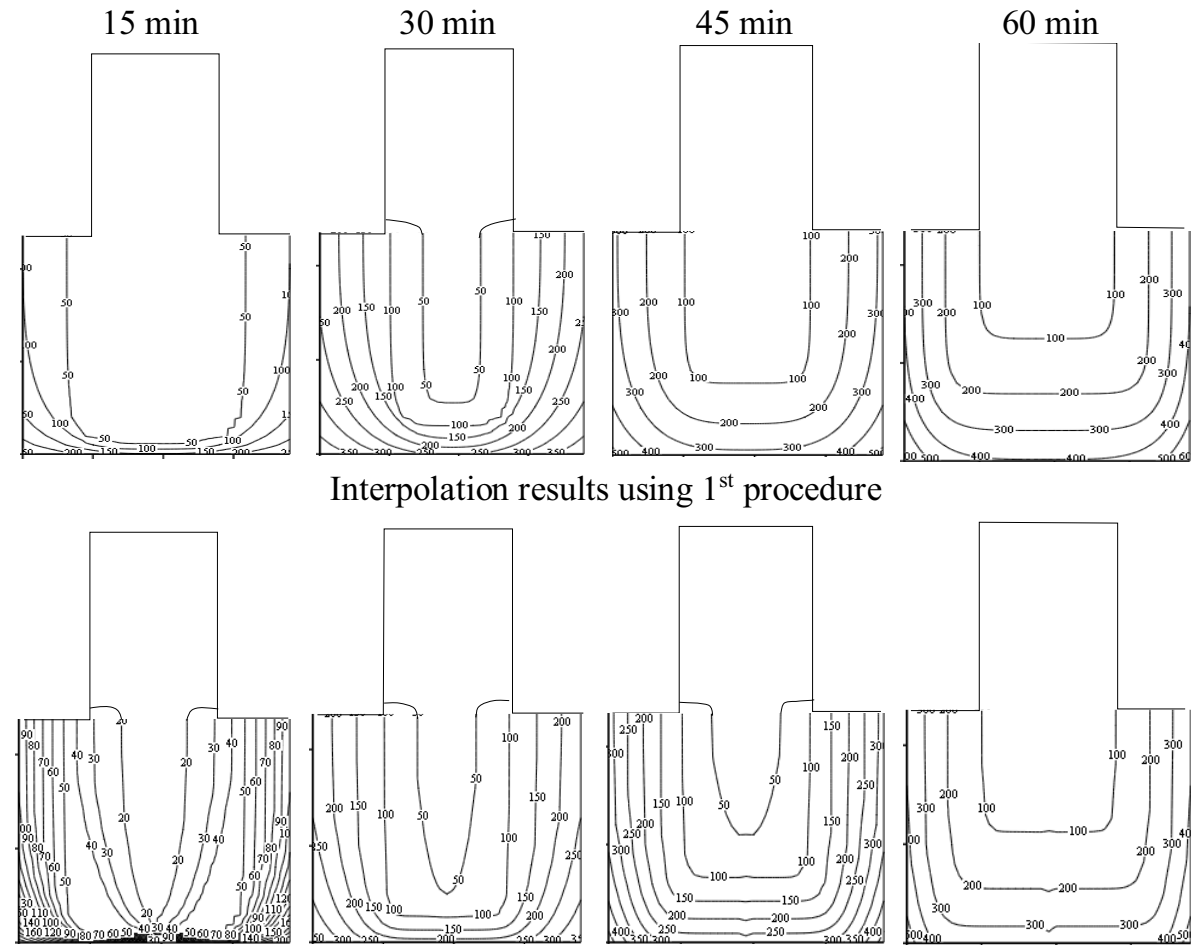

Interpolation results using $2^{\text {st }}$ procedure

Fig. 4. Temperature distribution patterns in sample reinforced concrete beams, determined using interpolation method.

Based on the study the fire resistance calculation method for reinforced concrete beams using experimental and calculation methods was developed. Its application is schematically shown in Fig. 6. 

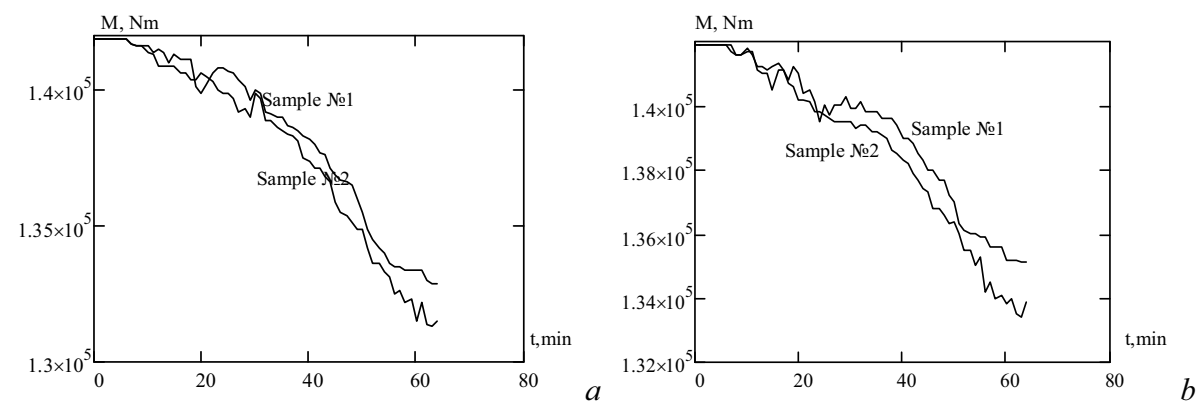

Fig. 5. Figure of the bearing capacity reduction for reinforced concrete beams according to the first interpolation method (a) and the second interpolation method (b).
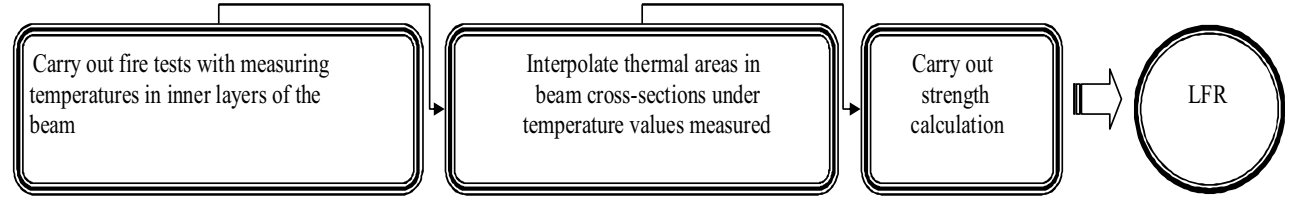

Fig. 6. Algorithm of operation life forecasting for reinforced concrete beams exposed to high temperatures using interpretation of the results of high-temperature tests.

As a result of the research the following conclusions were drawn.

1. The fire test of reinforced concrete beams was carried out and a temperature distribution in cross-section of beams was defined based on it by application of interpolation techniques developed.

2. The sequence of procedures of the strength calculation method based on temperature measuring in the inner layers of reinforced concrete beams was demonstrated.

3. Fire resistance of the reinforced concrete beams under question was evaluated based on the interpretation of the data obtained during the fire tests and using the proposed method of strength calculating.

\section{References}

1. State Building of Ukraine, Fire protection. Building structures fire safety, DBN V.1.1-72002, Kiev (2003)

2. DSTU B V.1.1-13:2007, Fire protection. Beams. Fire resistance testing method, Ukrarchbudinform, Kiev, 12 (2008)

3. DSTU B V.1.1-4-98, Fire protection. Building structures. Fire resistance test methods. General requirements, Ukrarchbudinform, Kiev (1998)

4. A. Omelchenko, S. Pozdeyev, Yu. Otrosh, [and others] Industrial building and engineering structures. Scientific and manufacturing magazine, 2/2014, 14 (2014)

5. EN 1992-1-2:2004 Eurocode 2: Design of concrete structures Part 1-2: General rules - Structural fire design, Brussels (2004). 